\title{
Hummingbirds Fuel Hovering Flight with Newly Ingested Sugar
}

\author{
Kenneth C. Welch Jr. ${ }^{1,1}$ \\ Bradley Hartman Bakken ${ }^{2}$ \\ Carlos Martínez del Rio ${ }^{2}$ \\ Raul K. Suarez ${ }^{1}$ \\ ${ }^{1}$ Department of Ecology, Evolution and Marine Biology, \\ University of California, Santa Barbara, California 93106- \\ 9610; ${ }^{2}$ Department of Zoology and Physiology, University of \\ Wyoming, Laramie, Wyoming 82071
}

Accepted 6/5/2006; Electronically Published 10/2/2006

\begin{abstract}
We sought to characterize the ability of hummingbirds to fuel their energetically expensive hovering flight using dietary sugar by a combination of respirometry and stable carbon isotope techniques. Broadtailed hummingbirds (Selasphorus platycercus) were maintained on a diet containing beet sugar with an isotopic composition characteristic of C3 plants. Hummingbirds were fasted and then offered a solution containing cane sugar with an isotopic composition characteristic of $\mathrm{C} 4$ plants. By monitoring the rates of $\mathrm{CO}_{2}$ production and $\mathrm{O}_{2}$ consumption, as well as the stable carbon isotope composition of expired $\mathrm{CO}_{2}$, we were able to estimate the relative contributions of carbohydrate and fat, as well as the absolute rate at which dietary sucrose was oxidized during hovering. The combination of respirometry and carbon isotope analysis revealed that hummingbirds initially oxidized endogenous fat following a fast and then progressively oxidized proportionately more carbohydrates. The contribution from dietary sources increased with each feeding bout, and by 20 min after the first meal, dietary sugar supported $\sim 74 \%$ of hovering metabolism. The ability of hummingbirds to satisfy the energetic requirements of hovering flight mainly with recently ingested sugar is unique among vertebrates. Our finding provides an example of evolutionary convergence in physiological and biochemical traits among unrelated nectar-feeding animals.
\end{abstract}

${ }^{1}$ Corresponding author; e-mail: k_welch@lifesci.ucsb.edu.

Physiological and Biochemical Zoology 79(6):1082-1087. 2006. (C) 2006 by The University of Chicago. All rights reserved. 1522-2152/2006/7906$6012 \$ 15.00$

\section{Introduction}

The habit of feeding on floral nectar has promoted convergence in morphological, behavioral, and physiological traits among insects, birds, and mammals. Hummingbirds (Trochilidae), a group of highly specialized nectar-feeding birds (Pyke 1980), share a number of traits with nectarivorous insects. In addition to hovering flight (Warrick et al. 2005) and small body size, both hummingbirds and nectar-feeding insects exhibit high mass-specific metabolic rates (Bartholomew and Casey 1978; Bartholomew et al. 1981; Suarez 1992, 2000) and possess large capacities for flight muscle carbohydrate oxidation (Suarez et al. 1986, 1990; O'Brien and Suarez 2001). In this article, we examine whether broadtailed hummingbirds (Selasphorus platycercus) share an additional trait with nectarivorous insects: the ability to support metabolism entirely with newly ingested sugar.

The hypothesis that hummingbirds support hovering flight with newly ingested dietary sugar emerged from respirometric studies. Respiratory quotient (RQ), which is equal to the rate of $\mathrm{CO}_{2}$ production $\left(\mathrm{V}_{\mathrm{CO}_{2}}\right)$ divided by the rate of oxygen consumption ( $\dot{\mathrm{V}}_{2}$; Ferrannini 1988), indicates that fasted hummingbirds switch from oxidizing lipids $(\mathrm{RQ}=0.7)$ to oxidizing carbohydrates $(\mathrm{RQ}=1.0$ ) within minutes of feeding (Suarez et al. 1990). Although RQ can distinguish between lipid and carbohydrate oxidation (Ferrannini 1988), it makes no distinction between endogenous and exogenous nutrient use. This analytical limitation, however, can be overcome by using elemental stable isotope analysis in a diet-shifting experimental design (O’Brien et al. 2002). Recently, Carleton et al. (2006) used this approach to quantify the fraction of resting metabolism supported by recently assimilated sugars and endogenous energy reserves in hummingbirds. Even though Carleton et al. (2006) took their measurements from restrained birds, their finding that $\sim 90 \%$ of metabolism is fueled with dietary sugar (Carleton et al. 2006) largely agrees with the RQ estimates of $\sim 1.0$ obtained from fed hummingbirds (Suarez et al. 1990). In this article, we combine respirometry and stable isotope analysis to determine (1) the substrate supporting metabolism during hovering flight in hummingbirds and (2) whether that substrate is endogenous or recently ingested. Our approach also allows us to estimate the rate of exogenous sugar oxidation in hovering hummingbirds (Adopo et al. 1994).

\section{Material and Methods}

The protocols we followed for this work were approved by the University of Wyoming's Institutional Animal Use and Care Committee. We report $\delta^{13} \mathrm{C}$ on a per mil (\%o) basis relative to 
the international carbon standard, Vienna Pee Dee Belemnite, where

$$
\delta^{13} \mathrm{C}=\frac{\left({ }^{13} \mathrm{C} /{ }^{12} \mathrm{C}\right)_{\text {sample }}-\left({ }^{13} \mathrm{C} /{ }^{12} \mathrm{C}\right)_{\text {standard }}}{\left({ }^{13} \mathrm{C} /{ }^{12} \mathrm{C}\right)_{\text {standard }}} \times 10^{3} .
$$

\section{Hummingbird Care and Experimental Design}

Using mist nets, we captured broadtailed hummingbirds (body mass $=2.8 \pm 0.3 \mathrm{~g}, n=8: 7$ male, 1 female) in Albany County, Wyoming $\left(41^{\circ} 20^{\prime} \mathrm{N}, 106^{\circ} 15^{\prime} \mathrm{W}\right)$. Captive hummingbirds were housed individually in wire-mesh cages $(0.6$ $\mathrm{m} \times 0.6 \mathrm{~m} \times 0.6 \mathrm{~m}$ ) on a $15: 9$ photoperiod (photophase: 0600 hours -2100 hours MDT) at $22^{\circ} \pm 2^{\circ} \mathrm{C}$. Before experimental manipulation, hummingbirds were fed ad lib. on two C3-derived maintenance diets for $\sim 150 \mathrm{~d}$. The first diet was a $13.0 \%$ (mass \%) solution of Nektar-Plus (Guenter Enderle, Tarpon Springs, FL) supplemented with vitamins (0.4\%; Nekton-S, Guenter Enderle) and beet sugar (5.0\%). The second maintenance diet was a $25.0 \%$ beet sugar solution. The $\delta^{13} \mathrm{C}$ of these maintenance diets were $-25.36 \%$ o $\pm 0.08 \%$ o $(n=3)$ and $-24.27 \%$ o $\pm .01 \%$ o $(n=3)$ for the Nektar-Plus and beet sugar solutions, respectively.

To determine the metabolic substrates used by hovering hummingbirds, we allowed them to feed ad lib. on a $20 \%$ solution of cane sugar after fasting overnight $(\sim 9 \mathrm{~h})$ or for $\sim 1$ h. The $\delta^{13} \mathrm{C}$ of this $\mathrm{C} 4$-derived cane sugar solution was $-11.34 \%$ o $\pm 0.04 \%$ o $(n=3)$. During the hover-feeding bouts, we simultaneously collected expired breath for mass spectrometry carbon isotope analysis and measured $\dot{\mathrm{V}}_{2}$ and $\dot{\mathrm{V}}_{\mathrm{CO}_{2}}$ as described below.

\section{Respirometry}

Respirometric measurement during hovering flight involved use of a feeder-mask apparatus designed after one used by Bartholomew and Lighton (1986). An inverted 50-mL conical tube served as reservoir for the cane sugar solution. A rubber stopper, pierced by an $8 \mathrm{~mm}$ (i.d.) glass tube of approximately $20 \mathrm{~cm}$ in length, was fitted to the bottom of the inverted tube. This glass tube was bent at $\sim 30^{\circ}$ approximately halfway along its length and fire polished so that the external opening had closed to roughly $2-3 \mathrm{~mm}$ in diameter. This opening made it possible for the hummingbirds to lick the cane sugar solution inside without excess spilling. A plastic cylinder (16 $\mathrm{mm}$ i.d.) was affixed to the glass feeding tube and served as a mask whenever the hummingbird accessed the feeder. Polyethylene tubing ( $6 \mathrm{~mm}$ i.d.) was fitted to an opening drilled through the side of the cylinder approximately halfway along the plastic mask. A photoresistor was attached to the bottom of the plastic mask adjacent to the open end. When the bird's head was inside the mask (during a feeding), the photoresistor was occluded.
Computer recordings of the resistance provided by the photoresistor thus allowed determining the timing and duration of a feeding event.

Immediately before data collection, the oxygen analyzer (FOXBOX, Sable Systems International, Las Vegas, NV) was calibrated with well-mixed ambient air drawn through the mask in the absence of a hummingbird. The carbon dioxide analyzer (CA-2A, Sable Systems International) was calibrated with $\mathrm{CO}_{2}$ free nitrogen gas (zero gas) and $0.5 \% \mathrm{CO}_{2}$ in nitrogen gas (Praxair, Danbury, CT). In each case, tubing was removed directly downstream of the mask and held inside a small reservoir into which flowed the calibration gas at a rate in excess of the flow rate of air pulled through the respirometry system. Air drawn through the chamber first passed through a column of Drierite desiccant (W. A. Hammond Drierite, Xenia, $\mathrm{OH}$ ) to remove water before passing through the carbon dioxide analyzer. After leaving the carbon dioxide analyzer, air passed through a Drierite-Ascarite-Drierite column (Ascarite II, Arthur H. Thomas, Philadelphia, PA), to scrub any carbon dioxide and additional water from the line, and then into the oxygen analyzer. Flow rate was controlled via adjustment of pump intensity by means of a mechanism internal to the oxygen

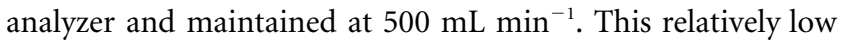
flow rate was chosen to facilitate ease and accuracy of timing of gas subsample collection. Oxygen analyzer, carbon dioxide analyzer, and photoresistor analog $(0-5 \mathrm{~V})$ output data were converted into a digital signal (Universal Interface II, Sable Systems International) before recording. Data were recorded at 0.05-sec intervals for $1 \mathrm{~h}$ using Expedata software (v. 1.0.1, Sable Systems International). Data collection took place from May 12 to May 20, 2005.

The STP-corrected oxygen depletion and carbon dioxide enrichment associated with each feeding event were determined by subtracting baseline values (estimated by the linear extrapolation of points directly before and after the feeding event in question). These baseline-corrected data were then converted to milliliters of gas by application of standard equations (Withers 1977). Finally, relative volumes (mL) of oxygen and carbon dioxide respired by the bird were obtained by integrating the gas depletion or enhancement peak over time (min) and used to calculate RQ. As discussed below, feeding events and associated respirometric data for which subsampled $\left[\mathrm{CO}_{2}\right]$ was $<1,000 \mathrm{ppm}$ were not included in our analyses.

Complementary measurements of $\dot{\mathrm{V}}_{2}$ and $\dot{\mathrm{V}}_{\mathrm{CO}_{2}}$ during hover feeding were obtained on a subset of hummingbirds ( $n=5: 4$ male, 1 female). Flow rate was held at $1,100 \mathrm{~mL}$ $\min ^{-1}$, and no expired breath subsamples were taken. Otherwise, the methodology adopted during this complementary data collection period was identical to that described above. These measurements were taken between May 4 and May 9, 2005. 


\section{Stable Carbon Isotope Analysis}

The breath samples we collected for stable isotope analysis during feeding bouts contained both respired and ambient $\mathrm{CO}_{2}$. Consequently, to estimate $\delta^{13} \mathrm{C}$ of respired breath $\left(\delta^{13} \mathrm{C}_{\text {breath }}\right)$, we used a two-part concentration-dependent mixing model adapted from Phillips and Koch (2002) such that

$$
\delta^{13} \mathrm{C}_{\text {breath }}=\frac{\delta^{13} \mathrm{C}_{\text {ambient }}\left(f_{\mathrm{a}}\right)+\delta^{13} \mathrm{C}_{\text {sample }}}{1-f_{\mathrm{a}}},
$$

where $\delta^{13} \mathrm{C}_{\text {sample }}$ is $\delta^{13} \mathrm{C}$ of air collected with a $60-\mathrm{mL}$ gastight syringe at a point approximately halfway between the mask and the desiccant column during a feeding bout. The $\delta^{13} \mathrm{C}_{\text {ambient }}$ is $\delta^{13} \mathrm{C}$ of air collected in the same manner as above when a hummingbird was not present at the mask. The $\delta^{13} \mathrm{C}_{\text {ambient }}$ did not vary within $\left(F_{1,13}=1.04, P=0.3276\right.$, repeatedmeasures ANOVA) or between $\left(F_{1,13}=0.03, P=0.8570\right.$, repeated-measures ANOVA) trials. Therefore, we assumed $\delta^{13} \mathrm{C}_{\text {ambient }}$ was $-8.76 \% \pm 1.01 \%$ o $(n=15)$ for our analyses. The fraction of $\mathrm{CO}_{2}$ in the gas sample from ambient air is $f_{\mathrm{a}}$. Ambient $\left[\mathrm{CO}_{2}\right]$ (ppm) was determined with a carbon dioxide analyzer immediately before a feeding bout. The $\left[\mathrm{CO}_{2}\right]$ of the respired breath sample (ppm) was determined using closedsystem respirometry (Vleck 1987).

Immediately after collection, we injected both breath and ambient samples into pre-evacuated 12-mL Exetainer vials (Labco, Buckinghamshire) until a positive pressure was achieved. Our mass spectrometry carbon isotope analysis was conducted as described previously (Carleton et al. 2004). To generate voltage output peaks between 2 and $5 \mathrm{~V}$ on the Micromass VG Optima continuous flow mass spectrometer coupled to a micro gas injector, the volume of sample gas we injected varied according to sample $\left[\mathrm{CO}_{2}\right]$. The $\left[\mathrm{CO}_{2}\right]$ in respired hummingbird breath samples ranged between 1,000 and $\sim 2,000 \mathrm{ppm}$, and we injected $1.5 \mathrm{~mL}$ of sample. If $\left[\mathrm{CO}_{2}\right]$ in a respired breath sample was $<1,000 \mathrm{ppm}$, we did not include it in our analyses: in general, breath samples containing $<1,000$ ppm $\mathrm{CO}_{2}$ were obtained from very brief or very sporadic feeding bouts. The $\left[\mathrm{CO}_{2}\right]$ in our ambient gas samples was $525 \pm$ $10 \mathrm{ppm}(n=15)$, and we injected $\sim 3.0 \mathrm{~mL}$ of sample.

After Carleton et al. (2006), we estimated the fraction of hovering metabolism supported by exogenous carbohydrate $\left(f_{\text {exo }}\right)$ as

$$
f_{\text {exo }}=\frac{\delta^{13} \mathrm{C}_{\text {breath }}-\delta^{13} \mathrm{C}_{\text {endo }}}{\delta^{13} \mathrm{C}_{\text {exo }}-\delta^{13} \mathrm{C}_{\text {endo }}}
$$

where $\delta^{13} \mathrm{C}_{\text {endo }}$ is the average $\delta^{13} \mathrm{C}$ breath from the first feeding following a fast (when only endogenous fuels are being oxidized) and $\delta^{13} \mathrm{C}_{\text {exo }}$ is the $\delta^{13} \mathrm{C}$ of the exogenous fuel. During the initial postfast feeding bout, $f_{\text {exo }}$ is, by definition, 0 .
Oxidation Rate of Exogenous Sugars

The oxidation rate of exogenous sugars $\left(M_{\mathrm{exo}}, \mathrm{mg} \mathrm{min}^{-1}\right)$ can be calculated as:

$$
M_{\text {exo }}=\frac{\dot{\mathrm{V}} \mathrm{CO}_{2} \times f_{\text {exo }}}{k},
$$

where $k$ is the volume of $\mathrm{CO}_{2}$ produced by glucose oxidation ( $k=0.7426 \mathrm{~mL} \mathrm{mg}{ }^{-1}$; Adopo et al. 1994) and $\dot{\mathrm{VCO}}_{2}$ is the organismal carbon dioxide production rate $\left(\mathrm{mL} \mathrm{min}^{-1}\right)$.

\section{Results and Discussion}

\section{Metabolic Substrate Use during Hover-Feeding Bouts}

Consistent with results obtained previously in rufous hummingbirds (Selasphorus rufus; Suarez et al. 1990), RQ values during hovering rapidly increased after feeding resumed. During the first feeding bout after a fast, RQ was $0.72 \pm 0.03$ $(n=5)$, indicating that the birds were primarily metabolizing fats. Twenty to $60 \mathrm{~min}$ after the resumption of feeding, RQ values were $0.93 \pm 0.05(n=42)$, indicating that the birds had switched to oxidizing mainly carbohydrates. As $>90 \%$ of $\dot{\mathrm{V}}_{2}$ (and $\dot{\mathrm{V}} \mathrm{CO}_{2}$ ) under these conditions is accounted for by mitochondrial respiration in fast-twitch oxidative flight muscles (Taylor 1987; Suarez 1992), this implies that in hover-feeding hummingbirds, these muscles derived most of their ATP from the oxidation of carbohydrate.

As RQ increased, $\delta^{13} \mathrm{C}_{\text {breath }}$ during the same feeding bouts also increased. The $\delta^{13} \mathrm{C}_{\text {breath }}$ during the first feeding bout following a fast was $-30.42 \%$ o $\pm 2.40 \%$ o $(n=5)$. This value, along with the RQ value of $0.72 \pm 0.03(n=5)$, indicates that fasted, hovering hummingbirds were mainly oxidizing endogenous fats that had been synthesized from C3-derived nutrients. This $\delta^{13} \mathrm{C}_{\text {breath }}$ value, however, is significantly more depleted in ${ }^{13} \mathrm{C}$ than the two C3-derived maintenance diets (Nektar-Plus: $t_{4}=-4.71, P=0.0092$; beet sugar: $\left.t_{4}=-5.72, P=0.0046\right)$. This may be the result of fractionation during fat synthesis from ingested sugars, depleting the ${ }^{13} \mathrm{C}$ content of fats relative to the original sugars from which they are synthesized (DeNiro and Epstein 1977). The degree to which $\delta^{13} \mathrm{C}$ of expired breath from fasted hummingbirds is depleted in ${ }^{13} \mathrm{C}$ with respect to the $\delta^{13} \mathrm{C}$ of the maintenance foods $(5.06 \%$ o vs. Nektar-Plus; $6.15 \%$ vs. beet sugar) may slightly underestimate the true degree of fractionation associated with the synthesis of fats, as fasted hummingbirds were likely oxidizing a small amount of carbohydrate and/or protein in addition to fat (RQ is slightly $>0.7$ ). Nevertheless, our fractionation estimates between dietary sugar and oxidized fat stores are intermediate of the values reported by DeNiro and Epstein (1977) and Carleton et al. (2006).

Another potential source of isotopic fractionation is the discrimination against ${ }^{13} \mathrm{C}$ that occurs as bicarbonate in the blood 


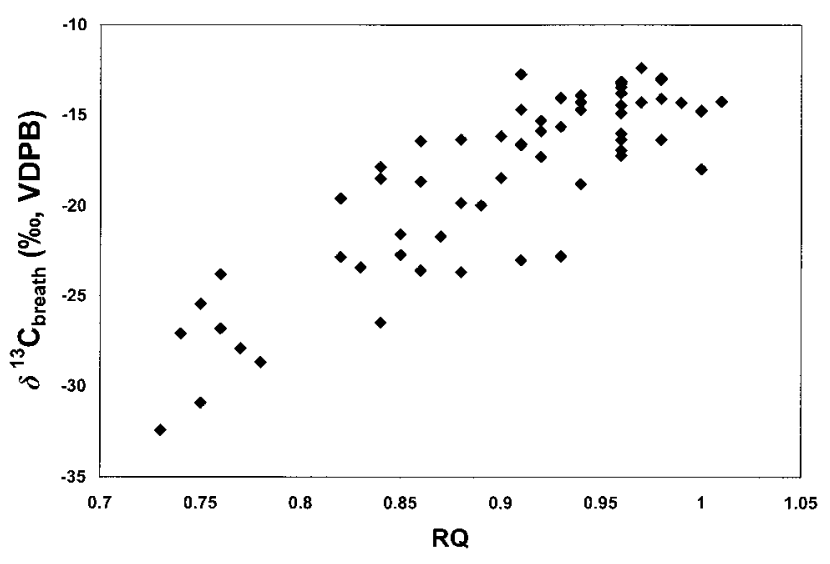

Figure 1. Relationship of respiratory quotient $\left(\mathrm{RQ}=\dot{\mathrm{V}}_{\mathrm{CO}_{2}} / \dot{\mathrm{V}}_{\mathrm{O}_{2}}\right)$ displayed during hover feeding to the $\delta^{13} \mathrm{C}$ value of expired $\mathrm{CO}_{2}\left(\delta^{13} \mathrm{C}_{\text {breath }}\right)$ during the same hover-feeding event in Selasphorus platycercus. Data are pooled from eight individuals ( $n=2-13$ per individual). There is a significant correlation between these two variables $\left(r_{64}=0.88, P<\right.$ $0.0001)$.

is released as $\mathrm{CO}_{2}$ by the lungs (Panteleev et al. 1999). However, the degree of fractionation between organismal bicarbonate/ carbonate pools and $\mathrm{CO}_{2}$ in expired breath is minimized during exercise (Pallikarakis et al. 1991; Massicotte et al. 1992). Thus, the fractionation between the blood bicarbonate pool and expired $\mathrm{CO}_{2}$ may be negligible in hovering hummingbirds.

The $\delta^{13} \mathrm{C}_{\text {breath }}$ values increased and stabilized at $-16.25 \%$ o \pm $3.10 \%$ o $(n=42)$ 20-60 min after the first feeding bout. This average value is significantly lower than the $\delta^{13} \mathrm{C}$ signature of the cane sugar offered during the hour of free feeding $\left(t_{41}=57.79\right.$, $P<0.0001)$. This is consistent with the RQ values being close to, but significantly $<1.0$, which suggests that C3-derived endogenous substrates contributed to fueling hovering flight. The RQ and $\delta^{13} \mathrm{C}_{\text {breath }}$ values are strongly positively correlated in all eight individuals $(r$ range $=0.80-1.0, P<0.01$ ). When we combined data from all individuals, RQ and $\delta^{13} \mathrm{C}_{\text {breath }}$ remained strongly and positively correlated (Fig. $1 ; r=0.88, P<0.0001$ ).

Using equation ( 3$), f_{\text {exo }}$ was $0.74 \pm 0.16(n=42)$ during the 20-60-min period after feeding resumed. Birds 27B, 29B, and 31B supported $83.8 \% \pm 5.7 \%, 86.5 \% \pm 4.3 \%$, and $84.0 \% \pm$ $6.3 \%$, respectively, of hovering metabolism with exogenous sugars during this period of feeding. Given our likely underestimation of $\delta^{13} \mathrm{C}_{\text {breath }}$, these high $f_{\text {exo }}$ values represent conservative estimates of the extent to which newly ingested sugar fuels hovering flight. Therefore, dietary sugar is likely to have supported most, if not all, of hovering metabolism in these individuals.

\section{Carbohydrate Oxidation Rates}

During the 20-60-min period after feeding resumed, $M_{\text {exo }}$ was $1.65 \pm 0.62 \mathrm{mg} \mathrm{min}^{-1}$ (or $9.18 \pm 3.45 \mu \mathrm{mol} \mathrm{g}{ }^{-1} \times \min ; n=$ 5 ; Table 1). As flight muscle mass accounts, on average, for $24.6 \%$ of total mass in broadtailed hummingbirds (Wells 1993), our estimate of flight muscle hexose oxidation rate was $2.32 \pm 0.86 \mathrm{mg} \min ^{-1}$ (or $12.86 \pm 4.76 \mu \mathrm{mol} \mathrm{g}^{-1} \times \mathrm{min}$; $n=5$; Table 1 ). This high rate of exogenous sugar oxidation falls within the maximum capacity for glucose phosphorylation (i.e., hexokinase activity $=18.4 \mu \mathrm{mol} \mathrm{g}^{-1} \times \mathrm{min}$ ) measured in flight muscles of congeneric rufous hummingbirds (Suarez et al. 1990).

The possible contribution of amino acid oxidation to hov-

Table 1: Steady state whole-animal and flight-muscle-specific exogenous sugar oxidation rates in hovering Selasphorus platycercus

\begin{tabular}{|c|c|c|c|c|c|c|c|c|c|}
\hline \multirow[b]{2}{*}{ Bird ID, Sex } & \multirow{2}{*}{$\begin{array}{l}\dot{\mathrm{V}} \mathrm{CO}_{2} / M_{\mathrm{b}}{ }^{\mathrm{a}} \\
(\mathrm{mL} \\
\left.\mathrm{h}^{-1} \times \mathrm{g}\right)\end{array}$} & \multirow[b]{2}{*}{$n$} & \multirow[b]{2}{*}{$\begin{array}{l}\delta^{13} \mathrm{C}_{\text {breath }}{ }^{\mathrm{b}} \\
(\%, \mathrm{VPDB})\end{array}$} & \multirow[b]{2}{*}{$f_{\text {exo }}{ }^{c}$} & \multirow[b]{2}{*}{$n$} & \multicolumn{2}{|l|}{$M_{\text {exo }}{ }^{\mathrm{d}}$} & \multicolumn{2}{|l|}{$M_{\mathrm{exo}} / M_{\mathrm{fm}}{ }^{\mathrm{e}}$} \\
\hline & & & & & & $\left(\mathrm{mg} \min ^{-1}\right)$ & $\left(\mu \mathrm{mol} \min ^{-1}\right)$ & $\begin{array}{l}(\mathrm{mg} \\
\left.\min ^{-1} \times \mathrm{g}\right)\end{array}$ & $\begin{array}{l}(\mu \mathrm{mol} \\
\left.\min ^{-1} \times \mathrm{g}\right)\end{array}$ \\
\hline $33 \mathrm{~B}, \mathrm{M}$ & $38.43 \pm .78$ & 4 & $-17.57 \pm 1.11$ & $.67 \pm .06$ & 3 & 1.56 & 8.67 & 2.17 & 12.05 \\
\hline $37 \mathrm{~B}, \mathrm{~F}$ & $36.61 \pm 1.55$ & 6 & $-19.06 \pm 2.63$ & $.60 \pm .14$ & 5 & 1.31 & 7.30 & 1.88 & 10.43 \\
\hline $31 \mathrm{~B}, \mathrm{M}$ & $48.78 \pm 1.78$ & 10 & $-14.40 \pm 1.20$ & $.84 \pm .06$ & 3 & 2.60 & 14.40 & 3.64 & 20.23 \\
\hline 39B, M & $38.67 \pm 1.73$ & 3 & $-22.80 \pm .83$ & $.40 \pm .04$ & 4 & .95 & 5.25 & 1.36 & 7.53 \\
\hline $\begin{array}{l}27 \mathrm{~B}, \mathrm{M} \\
\text { Mean } \pm \mathrm{SD}\end{array}$ & $35.08 \pm 1.24$ & 3 & $-14.43 \pm 1.09$ & $.84 \pm .06$ & 13 & $\begin{array}{c}1.85 \\
1.65 \pm .62\end{array}$ & $\begin{array}{c}10.27 \\
9.18 \pm 3.45\end{array}$ & $\begin{array}{c}2.54 \\
2.32 \pm .86\end{array}$ & $\begin{array}{c}14.08 \\
12.86 \pm 4.76\end{array}$ \\
\hline
\end{tabular}

Note. Data are presented as mean $\pm \mathrm{SD}$. $\mathrm{VCO}_{2}$ values were obtained in a complementary experiment during which no gas was subsampled for stable carbon isotope analysis. Individual average RQ values calculated for feedings taking place $20-60$ min after the first feeding following a fast during separate $\dot{\mathrm{V}}_{\mathrm{CO}}$ and $\delta^{13} \mathrm{C}_{\text {breath }}$ measurements do not significantly differ $(0.0589 \leq P \leq 0.7093)$, indicating data are compatible for use in calculation of $M_{\text {exo }}$. Flight-muscle-mass data are from Wells (1993). VPDB = Vienna Pee Dee Belemnite.

${ }^{a}$ Rate of $\mathrm{CO}_{2}$ production per g body mass.

${ }^{\mathrm{b}} \delta^{13} \mathrm{C}$ of expired breath.

${ }^{c}$ Fraction of hovering metabolism supported by exogenous carbohydrate.

${ }^{\mathrm{d}}$ Oxidation rate of exogenous sugars.

${ }^{\mathrm{e}} M_{\text {exo }}$ per $\mathrm{g}$ flight muscle (pectoralis and supracoracoideus). 
ering metabolism is worthy of consideration. While protein catabolism during long-distance flight may occur in hummingbirds (Carpenter et al. 1993), it is unlikely that protein breakdown would make a significant contribution to the fueling of aerobic metabolism during hover feeding because of the extremely high flux rates required (Suarez et al. 1990). The metabolic organization of hummingbird flight muscles (Suarez et al. 1986) is very similar to that of mammalian cardiac and aerobic skeletal muscles. Mammals, in general, fuel aerobic exercise mainly with carbohydrate and fat (Roberts et al. 1996). Consistent with this, protein accounts for $<5 \%$ of metabolized fuel in running ruff sandpipers (Philomachus pugnax; Vaillancourt et al. 2005).

Other vertebrates have much more limited capacities for directly fueling exercise metabolism with blood glucose (Weber et al. 1996) and possess locomotory muscles with limited capacities for glucose utilization during exercise (Vock et al. 1996; Weibel et al. 1996). Studies with humans reveal that only $15 \%-$ $30 \%$ of the metabolic rate during moderate exercise can be fueled with ingested sugars (Péronnet 2003).

\section{Evolutionary and Ecological Implications}

Our findings indicate that hummingbirds have evolved the capacity to use dietary sugar to directly fuel hovering flight as part of their invasion of a niche once exclusive to insects. Both sphingid moths and hummingbirds possess high biochemical capacities for carbohydrate and fat oxidation in their flight muscles (Suarez et al. 1986, 1990; O’Brien and Suarez 2001) and exhibit similar mass-specific metabolic rates during flight (Bartholomew and Casey 1978; Voigt and Winter 1999). Additionally, both nonfeeding moths and hummingbirds oxidize stored fats to fuel flight, while sugar-fed individuals oxidize carbohydrate (Suarez et al. 1990; O’Brien 1999; this study). Assuming the oxidation of hemolymph sugars, flight muscle hexokinase in hovering moths would likely operate at fractional velocities close to those estimated in hummingbirds (O'Brien and Suarez 2001). Unlike the well-characterized catabolic pathways in hummingbird flight muscles (Suarez et al. 1986, 1990), the nature of fat-oxidizing pathways in moth flight muscles is relatively obscure (Stevenson 1968; Crabtree and Newsholn $\rightarrow$ 1972; O'Brien and Suarez 2001). Despite this, hummingbirds and moths possess mechanisms that allow dynamic switching between carbohydrate and fat oxidation.

The direct oxidation of dietary sugar to provide the energ, for foraging flight is more energetically efficient than the alternative, which is to convert dietary sugar to fats first and then to oxidize fats to fuel foraging (Suarez et al. 1990). Our data on broadtailed hummingbirds add support to the hy $\rightarrow$ pothesis that foraging hummingbirds behave as "carbohydrate maximizers," which oxidize exogenous sugars during hovering flight so that endogenous fat reserves are spared. This maximizes both the net rate of fat deposition as well as the energetic efficiency with which dietary carbon is utilized (Suarez et al. 1990; Suarez and Gass 2002).

Insect nectarivores and hummingbirds appear to have converged in size, wingbeat frequency (Warrick et al. 2005), and metabolic rate (Bartholomew et al. 1981; Bartholomew and Casey 1978; Suarez 1992, 2000). The reliance of both hummingbirds and insects on dietary sugars to fuel hovering flight adds evidence to the notion that feeding on nectar has led to the evolution of similar morphological, physiological, and biochemical characteristics in these two groups of very distantly related organisms.

\section{Acknowledgments}

We are grateful to Dan Reuss at the Light Isotope Facility, Colorado State University, for technical help. Hummingbirds were captured under U.S. Fish and Wildlife and Wyoming Game and Fish permits issued to C.M.d.R. This work was supported by National Science Foundation grants IBN-0110416 to C.M.d.R. and IOB-0517694 to R.K.S.

\section{Literature Cited}

Adopo E., F. Péronnet, D. Massicotte, G.R. Brisson, and C. Hillaire-Marcel. 1994. Respective oxidation of exogenous glucose and fructose given in the same drink during exercise. J Appl Physiol 76:1014-1019.

Bartholomew G. and J. Lighton. 1986. Oxygen consumption during hover-feeding in free-ranging Anna hummingbirds. J Exp Biol 123:191-199.

Bartholomew G.A. and T.M. Casey. 1978. Oxygen-consumption of moths during rest, pre-flight warm-up, and flight in relation to body size and wing morphology. J Exp Biol 76:1125.

Bartholomew G.A., D. Vleck, and C.M. Vleck. 1981. Instantaneous measurements of oxygen consumption during preflight warm-up and post-flight cooling in sphingid and saturniid moths. J Exp Biol 90:17-32.

Carleton S.A., B. Hartman Bakken, and C. Martínez del Rio. 2006. Metabolic substrate use and the turnover of endogenous energy reserves in broad-tailed hummingbirds (Selasphorus platycercus). J Exp Biol 209:2622-2627.

Carleton S.A., B.O. Wolf, and C. Martínez del Rio. 2004. Keeling plots for hummingbirds: a method to estimate carbon isotope ratios of respired $\mathrm{CO}_{2}$ in small vertebrates. Oecologia 141:1-6.

$\rightarrow$ Carpenter F.L., M.A. Hixon, C.A. Beuchat, R.W. Russell, and D.C. Paton. 1993. Biphasic mass gain in migrant hummingbirds: body composition changes, torpor, and ecological significance. Ecology 74:1173-1182.

Crabtree B. and E.A. Newsholm. 1972. Activities of lipases and 
carnitine palmitoyltransferase in muscles from vertebrates and invertebrates. Biochem J 130:697-705.

$\rightarrow$ DeNiro M.J. and S. Epstein. 1977. Mechanism of carbon isotope fractionation associated with lipid synthesis. Science 197: 261-263.

$\rightarrow$ Ferrannini E. 1988. The theoretical bases of indirect calorim $\rightarrow$ Su etry: a review. Metabolism 37:287-301.

Massicotte D., F. Péronnet, G.R. Brisson, and C. HillaireMarcel. 1992. Oxidation of exogenous medium-chain frer $\rightarrow$ fatty acids during prolonged exercise: comparison with glucose. J Appl Physiol 73:1334-1339.

O'Brien D.M. 1999. Fuel use in flight and its dependence on nectar feeding in the hawkmoth Amphion floridensis. J ExI Biol 202:441-451.

$\rightarrow$ O'Brien D.M., M.L. Fogel, and C.L. Boggs. 2002. Renewable and non-renewable resources: amino acid turnover and al. location to reproduction in Lepidoptera. Proc Natl Acad Sci USA 99:4413-4418.

$\rightarrow$ O'Brien D.M. and R.K. Suarez. 2001. Fuel use in hawkmoth (Amphion floridensis) flight muscle: enzyme activities and flux rates. J Exp Zool 290:108-114.

$\rightarrow$ Pallikarakis N., N. Sphiris, and P. Lefebvre. 1991. Influence of the bicarbonate pool and on the occurrence of ${ }^{13} \mathrm{CO}_{2}$ in exhaled air. Eur J Appl Physiol 63:179-183.

$\rightarrow$ Panteleev N., F. Péronnet, C. Hillaire-Marcel, C. Lavoie, and D. Massicotte. 1999. Carbon isotope fractionation between blood and expired $\mathrm{CO}_{2}$ at rest and exercise. Respir Physiol 116:77-83.

Péronnet F. 2003. Oxydation des glucides ingérés pendant l'exercice. Actual Chim 8/9:34-37.

$\rightarrow$ Phillips D.L. and P.L. Koch. 2002. Incorporating concentration dependence in stable isotope mixing models. Oecologia 130: 114-125.

$\rightarrow$ Pyke G.H. 1980. The foraging behaviour of Australian honeyeaters: a review and some comparisons with hummingbirds. Aust J Ecol 5:343-369.

Roberts T., J. Weber, H. Hoppeler, E. Weibel, and C. Taylor. 1996. Design of the oxygen and substrate pathways. II. Defining the upper limits of carbohydrate and fat oxidation. J Exp Biol 199:1651-1658.

Stevenson E. 1968. Carnitine-independent oxidation of palmitate plus malate by moth flight-muscle mitochondria. Biochem J 110:105-110.

$\rightarrow$ Suarez R.K. 1992. Hummingbird flight: sustaining the highest mass-specific metabolic rates among vertebrates. Experentia 48:565-570.

$\rightarrow$. 2000. Energy metabolism during insect flight: bio- chemical design and physiological performance. Physiol Biochem Zool 73:765-771.

Suarez R.K., G.S. Brown and P.W. Hochachka. 1986. Metabolic sources of energy for hummingbird flight. Am J Physiol 251: R537-R542.

Suarez R.K. and C.L. Gass. 2002. Hummingbird foraging and the relation between bioenergetics and behaviour. Comp Biochem Physiol A 133:335-343.

Suarez R.K., J. Lighton, C. Moyes, G. Brown, C. Gass, and P. Hockachka. 1990. Fuel selection in rufous hummingbirds: ecological implications of metabolic biochemistry. Proc Natl Acad Sci USA 87:9207-9210.

Taylor C.R. 1987. Structural and functional limits to oxidative metabolism: insights from scaling. Annu Rev Physiol 49:135146.

Vaillancourt E., S. Prud'Homme, F. Haman, C.G. Guglielmo, and J.-M. Weber. 2005. Energetics of a long-distance migrant shorebird (Philomachus pugnax) during cold exposure and running. J Exp Biol 208:317-325.

$\rightarrow$ Vleck D. 1987. Measurement of $\mathrm{O}_{2}$ consumption, $\mathrm{CO}_{2}$ production, and water vapor production in a closed system. J Appl Physiol 62:2103-2106.

Vock R., E. Weibel, H. Hoppeler, G. Ordway, J. Weber, and C. Taylor. 1996. Design of the oxygen and substrate pathways. V. Structural basis of vascular substrate supply to muscle cells. J Exp Biol 199:1675-1688.

Voigt C.C. and Y. Winter. 1999. Energetic cost of hovering flight in nectar-feeding bats (Phyllostomidae: Glossophaginae) and its scaling in moths, birds and bats. J Comp Physiol B 169: 38-48.

Warrick D.R., B.W. Tobalske, and D.R. Powers. 2005. Aerodynamics of the hovering hummingbird. Nature 435:10941097.

Weber J., T. Roberts, R. Vock, E. Weibel, and C. Taylor. 1996. Design of the oxygen and substrate pathways. III. Partitioning energy provision from carbohydrates. J Exp Biol 199: 1659-1666.

Weibel E., C. Taylor, J. Weber, R. Vock, T. Roberts, and H. Hoppeler. 1996. Design of the oxygen and substrate pathways. VII. Different structural limits for oxygen and substrate supply to muscle mitochondria. J Exp Biol 199:1699-1709.

Wells D.J. 1993. Muscle performance in hovering hummingbirds. J Exp Biol 178:39-57.

Withers P.C. 1977. Measurement of $\dot{\mathrm{V}}_{2}, \dot{\mathrm{V}}_{\mathrm{CO}_{2}}$, and evaporative water loss with a flow-through mask. J Appl Physiol 42:120 123. 